\title{
Estado da Arte sobre Guarda de Filhos em Teses e Dissertações das Universidades Brasileiras
}

\author{
Daniela Moroni Ribeiro Quirino ${ }^{1}$ \\ Universidade Federal de Pernambuco, Recife, PE, Brasil \\ Jaileila de Araújo Menezes \\ Departamento de Psicologia e Orientações Educacionais da Universidade Federal \\ de Pernambuco, Recife, PE, Brasil
}

\begin{abstract}
Resumo
Este artigo consiste em um estudo do estado da arte nas teses e dissertações produzidas em universidades brasileiras, no período de 2004 até 2014 sobre guarda de filhos. Para tanto, consultamos as seguintes fontes de dados: Banco de Biblioteca Digital Brasileira de Teses e Dissertações e o Banco de Teses da Coordenação de Aperfeiçoamento de Pessoal de Nível Superior. Buscamos analisar a produção acadêmica sobre guarda, identificando seu contexto de produção e os temas que vêm sendo privilegiados nas discussões. Percebemos que o tema da guarda tem sido abordado, predominantemente, a partir de quatro focos ou categorias temáticas. A primeira reúne os estudos que problematizam o saber e a práxis da Psicologia no judiciário, sobretudo, no que se refere à interface da Psicologia e ao Direito de Família; a segunda categoria aborda decisões judiciais sobre guarda; a terceira trata das dinâmicas familiares em situação de disputa judicial de guarda; e a quarta, do lugar da criança em contexto de disputa de guarda. Identificamos lacunas tanto em relação a estudos que abordam as questões de gênero que influenciam as decisões judiciais quanto em relação a pesquisas que visibilizam os posicionamentos das crianças diante do tema.
\end{abstract}

Palavras-chaves: Guarda de filhos, psicologia jurídica, disputa de guarda.

\section{The State of the Art on Child Custody in theses and Dissertations from Brazilian Universities}

\begin{abstract}
This article consists of a study of the state of the art in theses and dissertations about child custody, produced in graduate programs of Brazilian universities, from 2004 to 2014. To this end, the following databases were consulted: the Brazilian Digital Library of Theses and Dissertations and the library of theses of the Higher Education Personnel Improvement Coordination. The goal was to analyze academic literature about child custody identifying which aspects of this issue have been favored in discussions, and its production context. It became evident that the issue of child custody has been approached predominantly from four points of view or thematic categories. The first is composed of studies which question the knowledge and practice of psychology in the judiciary, particularly concerning the interface of Psychology and Family Law; the second category involves juridical decisions about child custody; the third covers family dynamics during the juridical dispute of child custody; and the fourth discusses the place of the child in the context of custody dispute. Gaps were identified, both regarding studies which
\end{abstract}

Endereço para correspondência: Rua Carneiro Vilela, 510, Apto 801, Aflitos, Recife, PE, Brasil 52050-030. Fone: (81)985771310.E-mail: correiodedaniela@gmail.com e jaileila.araujo@gmail.com 
address gender issues which influence juridical decisions about custody, and also regarding research which highlight the point of view of the children about the subject.

Keywords: Child custody, legal psychology, custody dispute.

\section{Estado del Arte sobre Custodia de los Hijos en Tesis y Disertaciones de las Universidades Brasileñas}

\section{Resumen}

Este artículo es un estudio del estado del arte en tesis y disertaciones producidas en universidades brasileñas, en el período de 2004 hasta 2014, sobre custodia. Para esto, consultamos las siguientes fuentes de datos: Banco de la Biblioteca Digital Brasileña de Tesis y Disertaciones y el Banco de Tesis de la Coordinación de Perfeccionamiento de Personal de Nivel Superior. Buscamos analizar la producción académica sobre custodia, identificando su contexto de producción y los temas que vienen siendo privilegiados en las discusiones. Percibimos que el tema de la custodia ha sido abordado, predominantemente, a partir de cuatro categorías temáticas. La primera, reúne estudios que problematizan el saber y la praxis de la Psicología en lo judicial, sobre todo, en lo que refiere al vínculo entre Psicología y Derecho de Familia; la segunda categoría aborda las decisiones judiciales sobre custodia; la tercera, trata de las dinámicas familiares en la situación de disputa judicial de custodia; y la cuarta, del lugar del niño en el contexto de disputa de custodia. Identificamos lagunas tanto en relación a estudios que aborden las cuestiones de género que influyen las decisiones judiciales como en relación a investigaciones que visibilizen los posicionamientos de los niños frente al tema.

Palabras clave: Custodia de los hijos, psicología jurídica, disputa de la custodia.

Neste estudo realizamos um levantamento bibliográfico das teses e dissertações produzidas em programas de pós-graduação de universidades brasileiras, no período de 2004 até 2014, sobre guarda de filhos. A proposta foi analisar a produção acadêmica sobre guarda, identificando seu contexto de produção e os temas que vêm sendo privilegiados nas discussões.

Para tratar sobre a guarda de filhos, vale iniciar fazendo uma breve alusão histórica em relação às legislações dispostas sobre o mencionado tema. Em 1977, foi promulgada a Lei $n^{\circ} 6.515$ que regulava o divórcio. Nesta, o papel de cuidado e responsabilidade pelos filhos era atribuído ao genitor não culpado pela efetivação do divórcio, sendo, nos demais casos, delegado à mulher, conforme evidenciou o Art. 10, $\S 1^{\circ}$ desta Lei: "Se pela separação judicial forem responsáveis ambos os cônjuges; os filhos menores ficarão em poder da mãe ..." (Lei no 6.515, 1977).

Porém, em 1988, emergiu a discussão sobre o direito das crianças à convivência familiar plena, o que foi assegurado pela Carta Magna em seu Art. 227 (Constituição da República Federativa do Brasil, 1988). Ademais, o Estatuto da Criança e do Adolescente (ECA) endossou este direito fundamental da criança ao convívio com a família (Lei $\left.{ }^{\circ} 8.069,1990\right)$. Destarte, a legislação que dispôs sobre a guarda de filhos passou por alterações.

Nesse sentido, na busca por tentar garantir o melhor interesse da criança, o Código Civil de 2002 determinou que a guarda fosse atribuída àquele que apresentasse melhores condições para exercê-la, levando em consideração o grau de parentesco e afetividade estabelecida entre criança e guardião (Lei n ${ }^{\circ} 10.406,2002$ ). Ulteriormente, tal entendimento foi repensado e sofreu novas retificações em decorrência das imposições da Lei $n^{\circ} 11.698$, de 2008. Esta instruiu, disciplinou e preconizou a guarda compartilhada determinando sua aplicação sempre que possível. Assim, a modalidade unilateral de guarda seria determinada apenas de modo excepcional. Ficou estabelecido no Art. 584, § 2o do Código Cível que "quando não houver acordo entre a 
mãe e o pai quanto à guarda do filho, será aplicada, sempre que possível, a guarda compartilhada" (Lei no 11.698, 2008).

No ano de 2014 foi sancionada a Lei ${ }^{\circ}$ 13.058, que alterou novamente o Código Civil, esclarecendo sobre o significado da guarda compartilhada e dispondo acerca de sua aplicação. A Lei previu que quando não houvesse acordo acerca da guarda dos filhos, e ambos os genitores estivessem aptos a exercer a guarda, seria aplicada a guarda compartilhada, exceto se um dos pais declarasse judicialmente que não pretendia exercê-la (Lei n $\left.{ }^{\circ} 13.058,2014\right)$.

Resta-se evidenciado que a legislação tende a preconizar a aplicação da guarda compartilhada entendendo essa modalidade como a que atende ao melhor interesse da criança. No entanto, alguns estudos ${ }^{2}$ (Brito, 2002, 2007; Eizirik \& Bergmann, 2004) sinalizaram sofrimento psíquico dos filhos que vivem sob a guarda unilateral materna em virtude da ausência paterna.

Mas, pesquisa empreendida por Brito e Gonsalves (2013), com intuito de entender como a jurisprudência, emitida por alguns tribunais brasileiro $^{3}$, tem tratado da aplicação da guarda compartilhada, identificou um grande número ${ }^{4}$

Para maiores esclarecimentos consultar as pesquisas de Brito $(2002,2007)$, as quais apontam que a guarda unilateral materna pode contribuir para a fragilização do vínculo paterno filial, ou o estudo realizado por Eizirik e Gerbmann (2004) sinalizando que a ausência paterna pode contribuir para que crianças apresentem dificuldade no desenvolvimento psíquico (Eizirik \& Bergmann, 2004).

3 As instituições que contribuíram com o estudo foram: o Tribunal de Justiça do Estado do Rio de Janeiro (TJRJ), o Tribunal de Justiça do Rio Grande do Sul (TJRS) e o Tribunal de Justiça de Minas Gerais (TJMG).

4 Embora a pesquisa tenha adotado abordagem qualitativa dos dados, chamou atenção a desigualdade do número de decisões favoráveis à guarda compartilhada emitidas pelos tribunais estudados. Enquanto na jurisprudência do TJRJ 25\% dos acórdãos analisados foram favoráveis à guarda compartilhada, no TJRS não houve registro de decisões nesse sentido. No que se refere ao TJMG, dos 38 acórdãos, apenas quatro determinaram a aplicação da guarda compartilhada. Cabe ressaltar que a pesquisa analisou um total de 94 acórdãos, sendo 29 emitidos pelo TJRJ, 27 pelo TJRS e 38 de acórdãos contraindicando a aplicação dessa modalidade de guarda. Dentre as jurisprudências pesquisadas, identificaram-se algumas em que o argumento utilizado para justificar a aplicação da guarda unilateral materna foi a idade do infante. Ou seja, crianças em tenra idade deveriam estar sob a guarda unilateral materna. Contudo, a Lei $\mathrm{n}^{\mathrm{o}} 11.698$, de 2008, supracitada, não estabelece idade mínima como requisito para que seja aplicada a guarda compartilhada, desse modo não foi possível identificar o fundamento legal para tais decisões. A pesquisa ainda assinalou que os argumentos utilizados pelos operadores do direito para tomarem suas decisões encontravam-se em dissonância com resultados de pesquisas empreendidas na área das ciências humanas que demonstram a importância da plena convivência familiar para o bem-estar da criança (Brito \& Gonsalves, 2013).

Contudo, ainda predomina na atualidade o posicionamento do judiciário favorável à guarda unilateral materna. Isso pode ser evidenciado em estudo realizado pelo Instituto Brasileiro de Geografia e Estatística (IBGE, 2012). Neste, foi identificado que, dentre o número total ${ }^{5}$ de divórcios concedidos no Brasil, em 87,1\% dos casos a guarda dos filhos foi delegada a mulheres. Em apenas 5,4\% dos casos ficou determinada a guarda compartilhada. Portanto, ainda é preponderante, no judiciário, que a mulher se responsabilize pelos filhos.

Segundo Pinto, Rodrigues, Suzano, Meirelles e Figueiredo (2013), desde a promulgação da Constituição Federal Brasileira ficou garantida a igualdade entre homens e mulheres. Ademais, atualmente, a noção de que homens e mulheres são igualmente capazes de exercer a parentalidade, podendo ser individualmente responsáveis pelas crianças é reconhecida amplamente na literatura. No entanto, as práticas jurídicas, nas ações de guarda, dependem do entendimento do

pelo TJMG. Foram coletadas as decisões prolatadas desde que entrou em vigor a Lei no 11.698/08, em 12/08/14 até abril de 2010.

5 Na pesquisa foi contabilizado, no ano de 2012, um total de 341.600 divórcios tramitados em $1^{\mathrm{a}}$ instância, sem recursos ou lavrados por escrituras extrajudiciais. 
juiz, e, muitas vezes, o melhor interesse da criança é avaliado a partir de critérios subjetivos dos magistrados.

Ressaltamos ainda que estudo qualitativo foi desenvolvido utilizando como procedimento metodológico entrevistas semiestruturadas com mulheres estudantes que educavam seus filhos sem a presença paterna. Nesse estudo, ficou evidenciado que as mães vivenciaram dificuldades, angústias e estresse na maternidade devido à sobrecarga de responsabilidades e atividades acumuladas: domésticas, estudantis e de maternidade. As mulheres apontaram esta última como o papel exercido que apresenta maior complexidade e maturidade emocional (Borges, Thofehrn, $\&$ Meincke, 2005).

De fato, o exercício da responsabilidade parental sob os filhos ou a questão da guarda são complexos e envolvem atenção a múltiplos aspectos. Dentre eles estão: os caracteres psicossociais das crianças e das famílias em litígio judicial; as particularidades das diversas formas de ser família que vêm se afirmando na contemporaneidade (a exemplo, temos na atualidade a monoparentalidade feminina e masculina, a homoparentalidade e as famílias recompostas) e ao modo como os legisladores e o edifício jurídico pautam suas concepções em relação aos conflitos familiares ao longo da história.

Portanto, torna-se relevante que o campo de estudo sobre guarda discuta os mais diversos aspectos que circunscrevem o mencionado tema. Analisar a produção acadêmica sobre guarda, identificando seu contexto de produção e os temas que vêm sendo privilegiados nas discussões é fundamental para uma organização e sistematização desse campo de estudo, e é isso que nos propomos a fazer neste artigo.

\section{Método}

Para realizar a revisão de literatura acerca do tema guarda, utilizamos como fonte de busca, o Banco da Biblioteca Digital Brasileira de Teses e Dissertações (BDTD), onde consultamos as teses e dissertações defendidas no Brasil no período de 2004 a 2014, e o Banco de Teses da Coordenação de Aperfeiçoamento de Pessoal de Nível Superior (CAPES) ${ }^{6}$. Ressaltamos que tal busca teve como descritor o termo "guarda", uma vez que este abrangia estudos que utilizavam as seguintes palavras: guarda, guarda unilateral, guarda de filho, guarda de filhos, determinação judicial de guarda, disputa de guarda e demais sentenças em que houvesse tal termo. Pontuamos que a revisão bibliográfica contemplou as produções escritas em língua portuguesa apenas.

Ante o acervo apresentado, realizamos leitura dos títulos e resumo dos estudos, selecionando o material que atendia aos critérios de inclusão supracitados, isto é: tratar sobre guarda de filhos; estar redigido em língua portuguesa e ser uma tese ou dissertação defendida a partir do ano de 2004.

Selecionado o material, realizamos um estudo quantitativo, analisando o número de publicações segundo o local, ano de defesa e área de conhecimento em que se situavam as pesquisas. Posteriormente, fizemos um recorte nesses dados e focamos as produções em Psicologia. Realizamos uma leitura crítica dos resumos ou das produções na íntegra, de modo que também desenvolvemos uma análise qualitativa do acervo, tencionando compreender e articular os dados ao contexto e condições sócio-históricas em que foram produzidas as publicações.

\section{Resultados e Discussões}

Sobre as áreas de conhecimento que tem pesquisado acerca da temática em tela, identificamos que o Direito e a Psicologia apresentaram maior número de produções sobre guarda. Dentre o total das 42 produções encontradas, 15 situaram-se na área do Direito e 17, na de Psicologia. Em média, os mencionados campos compuseram $76 \%$ do total das produções. Vale res-

Ressalta-se que devido à mudança efetuada no sistema desta base de dados, ao efetuar a busca no banco de teses da CAPES, tivemos acesso apenas às teses e dissertações a partir de 2011, uma vez que após a implementação do novo sistema, o acervo ainda está sendo alimentado. Por isso não nos foi possível consultar as produções mais antigas. 
saltar que o Serviço Social também elaborou um número interessante de estudos - oito - quando comparado às demais áreas do conhecimento que produziram pesquisas acerca do tema, tendo ainda tanto a Filosofia quanto a Economia Doméstica produzido uma dissertação em suas respectivas áreas de saber.

No que se refere ao período de defesa dos estudos acadêmicos levantados, percebemos que em 2008 houve uma considerável ascensão do número de produções: aumentaram em 100\% em relação aos anos anteriores (entre 2004 e 2007 foram defendidas 11 produções, tendo, apenas em 2008, sido produzidas nove pesquisas). Salientamos que neste mesmo ano, 2008, houve alteração no Código Civil com a Lei no 11.698 , de 13 de junho de 2008. Nesta, há a instituição da guarda compartilhada, a qual, de acordo com a nova legislação, passaria a ser determinada sempre que possível, visando a atender o melhor interesse da criança.

Já em relação ao local em que foram publicadas as teses e dissertações, salientamos que a região Sudeste se mostrou como o lugar com maior concentração de pesquisas. Dentre as 42 produções pesquisadas nas cinco regiões do Brasil, 19 foram defendidas no sudeste. Detalhamos que o estado de São Paulo apresentou o maior quantitativo (17 produções).

Após apresentarmos um sucinto panorama das publicações, em termos quantitativos, realizaremos agora uma breve descrição e análise de como o tema guarda foi abordado nas dissertações e teses identificadas. Sinalizamos, desde já, que os estudos poderiam ser agrupados em quatro categorias, segundo os conteúdos de que tratam: a primeira problematiza o saber e a práxis da Psicologia no judiciário, principalmente, no que concerne à interlocução da Psicologia e Direito de Família; a segunda reúne estudos que tratam das decisões judiciais sobre guarda; a terceira aborda as relações familiares em situação de disputa judicial de guarda; e a quarta, o lugar da criança em contexto de guarda, ou a visão predominantemente clínica da criança enquanto objeto de disputa. Tais categorias serão apresentadas a seguir.
No que se refere à prática psi na interface Psicologia e Direito de Família, iniciaremos apresentando a pesquisa elaborada por Meister (2013) que visou a demonstrar as contribuições que a Psicologia Forense pode fornecer ao Direito, sobretudo, no que se refere às questões relacionadas às novas configurações familiares, que vêm se estabelecendo em nossa sociedade. No estudo, foi efetivada revisão bibliográfica acerca de temas situados na interface Direito e Psicologia, com foco no Direito de Família. Foi evidenciado o lugar da Psicologia como o saber especializado e relevante para afirmar, por meio de laudos, qual seria o melhor interesse da criança (Meister, 2013).

Corroborando com esse posicionamento, o estudo de enfoque psicanalítico, realizado por Queiroz (2010), tencionou investigar tanto quais as garantias de que o princípio do melhor interesse estava sendo atendido, no âmbito do judiciário e externamente a este; como também às percepções dos profissionais sobre os casos de disputa de guarda e as possíveis implicações subjetivas para os filhos que vivenciaram tal contexto. Os achados da pesquisa apontaram a relevância da Psicologia como o lugar do saber responsável por escutar a criança no âmbito do judiciário, evitando revitimizála, resguardando-a, sobretudo, por meio da utilização de recursos lúdicos no atendimento realizado a esta. Além disso, considerou adequado que o psicólogo desenvolvesse seu trabalho para além do foco pericial, estendendo suas intervenções e orientações aos genitores em litígio, visando levá-los a perceber os possíveis danos que o conflito vivenciado pode causar a criança (Queiroz, 2010).

O trabalho do psicólogo no judiciário também foi estudado por Lago (2008), sua pesquisa apontou que o principal instrumento avaliativo utilizado pelos profissionais foi a entrevista, realizada tanto com os pais quanto com os filhos. Também foram citados como instrumentos usados nas perícias, de modo complementar, as entrevistas a terceiros, as visitas domiciliares, escolares e os testes projetivos. Desses, os mais referidos foram o Desenho da Figura Humana, 
HTP e Rorschach. A prática profissional desenvolvida com a aplicação de testes ocorreu predominantemente entre os entrevistados residentes da região Sul do país.

Também foi realizada investigação acerca da formação extracurricular, do saber e da opinião dos profissionais acerca de temas emergentes no campo do Direito de Família, tais como: guarda compartilhada, síndrome de alienação parental e falsas denúncias de abuso sexual. Os achados indicaram que os psicólogos jurídicos tiveram experiências práticas com essas demandas, contudo, consideraram a relevância de que tais temáticas e também outros assuntos fossem trabalhados na graduação em Psicologia (Lago, 2008).

Ainda sobre o processo de avaliação psicológica no campo do judiciário, a pesquisa de Maiorki (2014) buscou elaborar, aplicar e avaliar a eficácia do protocolo de avaliação psicológica desenvolvida em contexto judicial de disputa de guarda. Para isso, o protocolo elaborado foi aplicado em onze famílias em disputa judicial pela guarda dos filhos. Depreendeu-se da avaliação desenvolvida com tal protocolo que dois pais apresentaram estresse em fase de exaustão; outros dois, depressão grave; seis, alienação parental. Ademais, uma criança teria vivenciado abuso sexual e outra, apresentado transtorno de conduta. A partir da avaliação da guarda, resultou que sete mães e três pais permaneceram com a guarda dos filhos. Desses casos pesquisados, houve decisão judicial em sete processos, nos quais a sentença se deu em consonância com os laudos elaborados a partir da utilização do protocolo em apreço na pesquisa (Maiorki, 2014).

Ainda sobre avaliação psicológica, Lago (2012), em sua tese de doutorado, propôs-se a construir um instrumento de avaliação psicológica - o Sistema de Avaliação do Relacionamento Parental (SARP) - para servir aos profissionais, psicólogos peritos, atuantes no judiciário. O SARP foi aplicado por perícia psicológica em processo de disputa de guarda, tendo demonstrado sua aplicabilidade e relevância para o campo. No que se refere às contribuições da Psicologia para o campo do Direito, ressalta-se que alguns autores também salientam a contribuição da psi- canálise para o judiciário (Oliveira, 2013; Queiroz, 2010).

Ferreira (2008) discutiu sobre o lugar da psicanálise quando inserida em instituição da justiça. Nesse estudo teórico, realizado com intuito de discutir e fundamentar, a partir da psicanálise, a escuta da criança em casos que envolvem disputa de guarda de filhos, foi ressaltado que a vontade expressa da criança talvez não atenda ao princípio do melhor interesse desta. Sua pesquisa sinalizou que a criança pode anunciar uma fala - como um pedido de ajuda, demandando à justiça soluções relacionadas a questões psíquicas empreendidas ao longo do seu desenvolvimento- $\mathrm{e}$ as soluções do Direito poderiam ou ainda deveriam divergir do desejo da criança (Ferreira, 2008).

Por meio da discussão travada na pesquisa, tornou-se proeminente a contribuição de profissionais da psicanálise no judiciário. Pois, a escuta psicanalítica visaria a uma compreensão ampla, pautada em fundamentos éticos da psicanálise, da manifestação da vontade da criança, perpassando pelos ditos e não ditos do sujeito, assim como pelo seu posicionamento na família. Ressalta-se que a psicanálise compreende a criança enquanto sujeito de desejo, sujeito dividido, do inconsciente, e nessa perspectiva a criança é escutada para além das limitações e da capacidade de discernimento ou de cognição, diferentemente do que preconiza a visão do Direito que se centra na ideia de capacidade de discernimento (Ferreira, 2008).

A autora questionou quais as fundamentações das determinações judiciais acerca da guarda, na medida em que a pesquisa dela teve como inspiração um caso atendido em atuação profissional enquanto servidora do Tribunal de Justiça. No mencionado caso, uma criança teria manifestado em juízo que gostaria de morar com a mãe e ver o pai apenas uma vez ao ano. Contudo, a família teria passado por avaliação psicológica previamente e a situação fora estudada com enfoque psicanalítico. O parecer teria apontado o sofrimento psíquico da criança possivelmente relacionado a uma fragilização do vínculo paterno filial. Ademais, foi evidenciado, nesse documento, que a solicitação da criança para residir 
com a mãe e colocar o genitor na justiça, parecia um modo encontrado pela infante de canalizar sua raiva e decepção com o pai. Tal posicionamento possivelmente esteve em dissonância com a manifestação da criança em audiência. Em decisão judicial, o magistrado teria sido favorável à guarda unilateral materna, tendo fornecido a justificativa de que fosse respeitada a vontade da menina (Ferreira, 2008).

Em relação às decisões judiciais sobre guarda, tema tratado, predominantemente, pelos estudos que compõem a segunda categoria, assinalamos a pesquisa realizada por Meister (2013), que focou analisar a aplicação da Lei da Guarda Compartilhada, por meio da análise de 40 processos com ações de guarda, contidos no banco de dados dos Tribunais, disponíveis na internet. Evidenciou-se no estudo que os magistrados têm determinado essa modalidade de guarda com cautela, uma vez que há divergências jurisdicionais acerca do assunto, tais como: se a criança deve ou não alternar o local de residência; se é ou não imprescindível que os genitores estabeleçam relação harmoniosa entre si. Ademais, tornou-se proeminente a necessidade de maiores esclarecimentos na lei sobre a guarda compartilhada ao considerá-la como modelo preferencial de guarda a ser exercitada (Meister, 2013).

No que concerne à perspectiva dos operadores do Direito sobre guarda, Colcerniani (2010) realizou estudo qualitativo buscando conhecer as representações sociais de magistrados atuantes em Varas de Família acerca da família monoparental feminina e da guarda de filhos. Visou ainda a identificar se havia relação entre tais representações e as práxis dos magistrados, expressas nas sentenças judiciais. A partir de realização de entrevistas individuais, aplicação de questionários sociodemográficos e análises documentais, restou evidenciado que as representações sociais sobre guarda de filhos e família monoparental feminina estariam associadas, respectivamente, à proteção dos filhos e a dificuldades financeiras. No que se refere às relações entre essas representações sociais e as sentenças judiciais analisadas, foi verificado que estas estariam ligadas à representação social da guarda, mas não foram identificadas vinculações entre as representações sociais de famílias monoparentais femininas e os despachos estudados.

Em outro estudo, empreendido por Cezar-Ferreira (2013), foram realizadas entrevistas a desembargadores e juízes de Varas de Família com questionamento sobre a relevância da inclusão do estatuto da guarda compartilhada na lei, uma vez que esta determina que tal modalidade de guarda seja adotada sempre que possível. $\mathrm{O}$ estudo apontou os seguintes achados: no que se refere à aplicação da lei, ficou evidenciada a importância de as decisões judiciais atenderem ao princípio de melhor interesse da criança; também foi relatado que, embora fosse desejável a determinação da guarda compartilhada, esta exigia uma relação conjugal minimamente harmônica para que fosse executada pelos guardiões, caso contrário, no entender dos referidos operadores do Direito, os filhos poderiam estar desprotegidos. Ademais, restou evidente que a magistratura, no campo do Direito de Família, é influenciada pela perspectiva psicojurídica, visto que se recorre às contribuições da psicologia como subsídio para a determinação da guarda (Cezar-Ferreira, 2013).

Já no que se refere às pesquisas que tratam das relações familiares em situação de disputa judicial de guarda, tema tratado pela terceira categoria que identificamos, é possível assinalar o trabalho realizado por Isotton (2011), que estudou famílias pós-divórcio aspirando a compreender o exercício da paternidade quando o pai possuía a guarda unilateral dos filhos. Utilizando estudos de caso como técnica metodológica, identificou que o exercício da paternidade era desenvolvido a partir da responsabilidade paterna pela educação, saúde, alimentação, lazer, segurança e sustento financeiro dos filhos. Os genitores costumavam contar com o apoio da família extensa para dar conta das responsabilidades e tarefas acumuladas. Esses pais também demonstraram sentir prazer pelo exercício da paternidade. A adoção do modelo de paternidade exercido pelos entrevistados era, de alguma forma, espelhada nos modelos parentais vivenciados anteriormente pelos entrevistados, quando foram filhos. Seja nos casos em que os entrevistados apresentaram uma imagem paterna positiva, 
concordando e admirando a paternidade vivenciada na infância, seja no caso oposto, quando os entrevistados tentavam exercer a paternidade se opondo à experiência vivida na relação com pai na infância. Ademais, restou perceptível que a visão de gênero masculino dos entrevistados era distinta do modelo tradicional, de modo que $\mathrm{o}$ afeto e o vínculo estabelecido entre pai e filho foram pontos marcantes nos relatos, tendo as crianças entrevistadas, de modo geral, corroborado com as afirmações paternas acerca desse vínculo (Isotton, 2011).

Outra pesquisa qualitativa, desenvolvida por Bottoli (2010), teve o intuito de conhecer, a partir da perspectiva paterna, o modo como a parentalidade se constituía em contexto de separação e guarda. Para tanto, foram efetuadas entrevistas com sete pais que vivenciavam esse contexto familiar. Os relatos paternos indicaram a separação como momento gerador de mudanças para o exercício da paternidade, sobretudo, no que diz respeito à convivência entre pais e filhos. Também foram identificadas dificuldades relacionadas ao fim da conjugalidade e permanência da parentalidade, e ao desejo dos pais em estarem mais próximos dos filhos. No que se refere à guarda, os pais sinalizaram anseio de maior convívio com os filhos, mas, concomitantemente, consideraram a mãe como a figura "naturalmente" designada para assumir o lugar da detenção da guarda. Finalmente, ficou evidente a busca diária paterna por exercer a paternidade de modo mais participativo e presente, nos moldes da paternidade contemporânea (Bottoli, 2010).

Na pesquisa desenvolvida por Juras (2009), o autor focou compreender como se apresentavam os papeis parentais e conjugais em contexto de divórcio, considerando famílias que recorreram ao judiciário para pleitear a guarda ou regulamentar as visitas aos filhos (Juras, 2009). A pesquisa fundamentou-se na Teoria Familiar Sistêmica e utilizou como instrumentos metodológicos entrevistas semiestruturadas com as famílias, genograma familiar, visita domiciliar e desenho da família. Contribuíram com o estudo três famílias, com filhos menores de doze anos, em contexto de litígio judicial, conforme supracitado. Ficou evidenciado que os pais apresentaram dificuldade em diferenciar a relação conjugal da parental, inclusive, investindo mais naquela em detrimento desta. Também foi indicado que o modelo comunicacional predominantemente estabelecido denotou alguns caracteres, quais sejam: uma comunicação rígida, autoritária e violenta; a resistência em realizar contatos diretos com o outro genitor, recorrendo-se a terceiros - filhos, familiares e profissionais da justiça - para o intermédio do contato; a competitividade, a disputa por poder e a autopromoção associada à responsabilização do outro pelo conflito (Juras, 2009).

Outro estudo, de cunho qualitativo, foi realizado por Silva (2009) visando a verificar como ocorreu a parentalidade quando ex-cônjuges elegeram a modalidade da guarda compartilhada para se responsabilizarem pelos filhos. $\mathrm{O}$ autor percebeu, após a realização de entrevistas aos ex-casais, que os genitores desenvolveram a parentalidade de modo mais igualitário, participativo e próximo dos filhos. Embora ainda vivenciando certas dificuldades, como questões relacionadas ao respeito à individualidade de cada genitor, os pais enfrentam os desafios com o intuito maior de priorizar o interesse dos filhos. Foram identificados fatores facilitadores e dificultadores do exercício da parentalidade na guarda compartilhada. Os facilitadores estariam ligados à distinção da relação entre conjugalidade e parentalidade e à manutenção do diálogo acerca dos interesses filiais. Já os dificultadores seriam: a comunicação prejudicada entre os pais, estilos educacionais diferentes, a desigual divisão das atribuições parentais cotidianas e a competitividade entre esses genitores. Por fim, identificou-se que a escolha dos entrevistados pela guarda compartilhada foi motivada por orientação proveniente dos advogados ou de outros profissionais atuante na área do Direito.

Schneebeli (2011) desenvolveu pesquisa buscando investigar as representações sociais da guarda de filhos e da separação. Foram utilizadas entrevistas e aplicados questionários para 15 mães e 15 pais tratando sobre essa temática. Os resultados indicaram que, no período de planejamento e reflexão sobre a separação, a preocu- 
pação dos sujeitos girou em torno do bem-estar psíquico dos filhos; já no momento da efetivação da separação, os participantes consideraram que os filhos deveriam permanecer sob a responsabilidade materna, sendo necessário, contudo, considerar a opinião filial acerca da guarda e das visitas; no momento pós-divórcio, a preocupação voltou a incidir sobre o bem-estar psicológico das crianças e a importância da convivência próxima dos genitores com os filhos. Ademais, os seguintes elementos foram associados à representação social da guarda unilateral: guarda materna, exclusividade de um genitor e exclusão do outro, e desacordo entre os ex-cônjuges; já em relação à representação social da guarda compartilhada os componentes que se tornaram evidentes foram: a igualdade de convívio entre genitores e filhos, a divisão entre os genitores de responsabilidades sobre os filhos, acordo e/ou amizade entre os genitores, além de diversidade de ambientes.

Restou perceptível, finalmente, que a predominância da adesão à guarda unilateral em detrimento da guarda compartilhada pareceu relacionada às representações sociais de maternidade e paternidade em que a mãe figura de modo fundamental no papel da educação dos filhos (Schneebeli, 2011).

$\mathrm{Na}$ quarta categoria, que trata do lugar da criança em contexto de disputa judicial de guarda, ou da visão predominantemente clínica da criança enquanto objeto de disputa, identificamos alguns estudos, os quais apresentamos a seguir.

A pesquisa realizada por Queiroz (2010), de caráter exploratório, teve os seguintes objetivos: investigar as garantias de que o princípio do melhor interesse da criança é atendido no campo jurídico e para além deste; a percepção dos profissionais, cujas práticas situam-se no contexto judicial de disputa de guarda, em relação à esse princípio; as justificativas ressaltadas pelos genitores para estarem em litígio e as implicações subjetivas para as crianças ao vivenciar tal contexto. Para tanto, foram entrevistados psicólogos, assistentes sociais e juristas. O estudo indicou que profissionais atuantes no campo do judiciário ressaltaram os seguintes elementos como em consonância com o melhor interesse da criança: a busca por preservá-la, preconizando tanto sua não vitimização em decorrência dos conflitos conjugais como sua convivência com os genitores. Ademais, foi percebido que a determinação judicial não garantia o atendimento ao melhor interesse da criança, ainda que se respaldando no Estatuto da Criança e do Adolescente, nas provas documentais das acusações, nas escutas das crianças em audiências, nas periciais interprofissionais e em medidas coercitivas.

Ficou evidenciado ainda, a partir de entrevistas realizadas com profissionais da área psi, que as crianças em contexto de disputa de guarda podem ser invisibilizadas. Isso em decorrência tanto de frustrações ou mágoas advindas da dissolução conjugal, que posicionam a criança como mais um objeto de disputa, quanto de interesses secundários relacionados aos pagamentos da pensão alimentícia. Nesse sentido, as crianças sentem-se angustiadas e em resposta a essa dinâmica familiar conflituosa podem apresentar sintomas patológicos (Queiroz, 2010).

Outra pesquisa, realizada por Juras (2009), teve como participantes três famílias em que houve divórcio, com filhos pequenos (menores de 12 anos), demandantes do judiciário com processos de disputa de guarda ou regulamentação de visitas. Foram utilizados como instrumentos entrevista semiestruturadas, genograma, visitas domiciliares e desenho de família, usado com as crianças. Ficou demonstrado que nesse contexto os filhos foram incluídos nos conflitos conjugais, tendo estes se sobressaltado em relação ao exercício da parentalidade. A comunicação entre os genitores foi marcada por competições, autoritarismo e evitamento de contatos diretos. Os filhos externaram a insatisfação e o sofrimento sentidos em relação ao conflito conjugal. Concomitantemente, demonstraram estratégias de enfrentamento para lidar com o contexto, tais como: fortalecimento da fratria e buscas para além do âmbito familiar (Juras, 2009).

Após apresentarmos um panorama acerca do que se tem discutido no campo da guarda de filhos, é possível assinalar nossa impressão de que na presente revisão de literatura, ao tratar sobre crianças, os estudos, predominantemente, 
pareceram partir do pressuposto de que a dinâmica familiar em litígio judicial e pós-divórcio implicam inscrições negativas ao desenvolvimento da criança. Nesse sentido, os estudos supra-apresentados podem ter se pautado em concepção desenvolvimentista das crianças, que possivelmente as posicionam como um "ainda não" ou um "vir a ser", sem considerar suas potencialidades no seu atual momento. Segundo Castro (2001), tal concepção, também explorada pelo Direito, desprivilegia as crianças no que se refere à capacidade de fazer jus, plenamente, a direitos civis e políticos. A criança posicionada nesse lugar torna-se um objeto dependente, o que se relaciona à sua condição de necessidade de proteção da família e do Estado ressaltada por nosso edifício jurídico (Castro, 2001).

Embora seja preconizado que a determinação da guarda deva atender ao melhor interesse da criança, nessas pesquisas o lugar de saber sobre tal interesse é ocupado por adultos, não identificamos estudos em que as crianças fossem escutadas. Nas quatro produções (Isotton, 2011; Juras, 2009; Lago, 2012; Maiorki, 2014) em que foram efetivadas interlocuções com crianças, isto é, com os filhos de casais em contexto de disputa de guarda, as crianças ou adolescentes foram convidados a compor a cena da pesquisa enquanto coadjuvantes - sobretudo figurando como um informante da dinâmica familiar em questão. Assim, as considerações das crianças foram utilizadas para corroborar ou não com os posicionamentos de outros familiares (Isotton, 2011), ou para auxiliar na construção ou desenvolvimento de instrumentos de avaliação psicológica (Lago, 2012; Maiorki, 2014). As crianças não figuraram enquanto atores principais. Não identificamos estudos que visassem à compreensão dos objetos de pesquisa a partir da perspectiva das crianças. Isso nos transmitiu a impressão de que na cena judicial em que se determinam os cuidados, as questões de educação e de sustento financeiro da criança, estas foram silenciadas, invisibilizadas.

Demonstrar como as crianças se posicionam pode vir a contribuir com o campo de estudos sobre guarda, dando visibilidade às mesmas, o que possivelmente se constituirá como um subsídio para os fundamentos das decisões judiciais sobre guarda. Além disso, é relevante uma produção que vise a estimular a reflexão crítica acerca do lugar em que a criança pode ser posicionada, diante de profissionais que atuam no judiciário, o que poderá contribuir para a formação destes.

Identificamos ainda, nas dissertações e teses selecionadas, que as pesquisas utilizaram predominantemente um método de abordagem qualitativa, sendo poucos os estudos quantitativos. A entrevista consistiu na técnica mais utilizada dentre os instrumentos de pesquisa.

Foi possível perceber também a escassez de estudos que abordassem as questões de gênero influentes nas decisões judiciais sobre guarda unilateral materna. Acerca desse tema, chamou atenção apenas o trabalho de Schneebeli (2011) em que foram trazidas para as discussões sobre guarda as representações sociais de maternidade como possíveis justificativas para a predominância das decisões judiciais favoráveis à guarda unilateral materna em detrimento da guarda compartilhada.

\section{Considerações Finais}

Realizado o levantamento de teses e dissertações produzidas nas universidades brasileiras no período de 2004 até 2014, buscamos analisar a produção acadêmica sobre guarda identificando seu contexto de produção e os temas que vêm sendo privilegiados nas discussões.

Percebemos que as produções sobre guarda de filhos aumentaram no ano de 2008, período em que foi alterado o Código Civil para instituir e privilegiar a guarda compartilhada, após longos anos em que a guarda unilateral materna era preconizada.

Ademais, identificamos também que o tema da guarda tem sido abordado, predominantemente, a partir de quatro focos ou categorias temáticas. A primeira reúne os estudos que problematizam o saber e a práxis da Psicologia no judiciário, sobretudo, no que se refere à interface da Psicologia e o Direito de Família; a segunda categoria de teses e dissertações envolve estudos sobre as decisões judiciais sobre guarda; a terceira abrange estudos que abordam as dinâ- 
micas familiares em situação de disputa judicial de guarda de filhos e a quarta aborda o lugar da criança em contexto de disputa de guarda, ou a visão predominantemente clínica da criança enquanto objeto de disputa.

Restou evidenciado ainda que a maior parte dos estudos apresenta uma abordagem qualitativa metodológica, sendo poucas as teses e dissertações voltadas para o tratamento quantitativo dos dados. Além disso, identificamos uma lacuna em relação à estudos que abordassem as questões de gênero que influenciam nas decisões judiciais sobre guarda unilateral materna. Ainda percebemos uma ausência de pesquisas que visibilizavam os posicionamentos das crianças em relação ao contexto de disputa de guarda, e tampouco encontramos estudos que buscassem a compreensão dos objetos de pesquisa a partir da perspectiva das crianças, já que, em tese, as decisões judiciais devem ser tomadas visando a atender seus interesses.

\section{Referências}

Borges, C. J., Thofern, M. B., \& Meincke, S. M. K. (2005). Mulheres estudantes criando seus filhos no contexto da família monoparental. Família, Saúde e Desenvolvimento, 7(1), 32-41. Recuperado em http://ojs.c3sl.ufpr.br/ojs/index.php/ refased/article/viewArticle/8051

Bottoli, C. (2010). Paternidade e separação conjugal: A perspectiva do pai (Dissertação de mestrado, Universidade Federal de Santa Maria, RS, Brasil). Recuperado em http://cascavel. cpd.ufsm.br/tede/tde arquivos/41/TDE-201102-22T111507Z-3056/Publico/BOTTOLI,\%20 CRISTIANE.pdf

Brito, L. M. T. (2002). Impasses na condição da guarda e da visitação - O palco da discórdia. In Anais do XXIII Congresso Brasileiro de Direito de Família (pp. 433-448). Belo Horizonte, MG: Associação de Pais e Mães Separados.

Brito, L. M. T. (2007). Família pós-divórcio: A visão dos filhos. Psicologia Ciência e Profissão, 27(1), 32-45. doi:10.1590/S1414-98932007000100004

Brito, L. M. T., \& Gonsalves, E. N. (2013). Guarda compartilhada: Alguns argumentos e conteúdos da jurisprudência. Revista Direito $G V, 9(1)$, 299-317. Recuperado em http://www.scielo. br/scielo.php?script $=$ sci arttext\&pid $=\mathrm{S} 1808$ $-24322013000100011 \& \operatorname{lng}=\mathrm{en} \& n r m=$ iso

Castro, L. R. (2001). Da invisibilidade à ação: Crianças e jovens na construção da cultura. In L. R. Castro (Ed.), Crianças e jovens na construção da cultura (pp 19-461). Rio de Janeiro, RJ: NAU.

Cezar-Ferreira, V. A. (2013). Guarda compartilhada: Uma visão psicojurídica do relacionamento parental pós-separação ou divórcio (Tese de doutorado, Pontifícia Universidade Católica de São Paulo, SP, Brasil). Recuperado em http:// busca.ibict.br/SearchBDTD/search.do?comman $\mathrm{d}=$ search\&q=+assunto:\%22Psychojuridical $\% 20$ view\%22

Colcerniani, C. B. (2010). Família monoparental feminina e guarda de filhos: $O$ que pensam os juízes de direito das varas de família? (Dissertação de mestrado em Psicologia, Universidade de Brasília, DF, Brasil) Recuperado em http:// repositorio.unb.br/handle/10482/6199

Constituição da República Federativa do Brasil de 1988. (1988). Brasília, DF. Recuperado em http://www.planalto.gov.br/ccivil_03/Constituicao/Constituicao.htm

Eizirik, M., \& Bergmann, D. S. (2004). Ausência paterna e sua repercussão no desenvolvimento da criança e do adolescente: Um relato de caso. Revista de Psiquiatria do Rio Grande do Sul, 26(3), 330-336. doi:10.1590/S010181082004000300010

Ferreira, M. T. F. (2008). A manifestação da vontade da criança na disputa judicial da guarda: Escuta psicanalítica (Dissertação de mestrado, Universidade Federal do Rio Grande do Norte, Natal, RN, Brasil). Recuperado em http:// www.repositorio.ufrn.br:8080/jspui/handle/123456789/17429

Instituto Brasileiro de Geografia e Estatística. (2012). Estatísticas do Registro Civil. Recuperado em http://biblioteca.ibge.gov.br/visualizacao/periodicos/135/rc_2012_v39.pdf

Isotton, R. (2011). Paternidade em famílias pósdivórcio cujo pai detém a guarda unilateral dos filhos (Dissertação de mestrado em Psicologia Clínica, Universidade do Vale do Rio dos Sinos, São Leopoldo, RS, Brasil). Recuperado em http://www.repositorio.jesuita.org.br/bitstream/handle/UNISINOS/3997/RogerioIsotton. pdf? sequence $=1 \&$ is Allowed $=y$ 
Juras, M. M. (2009). Papéis conjugais e parentais na situação de divórcio destrutivo com filhos pequenos (Dissertação de mestrado em Psicologia, Universidade de Brasília, DF, Brasil). Recuperado em http://repositorio.unb.br/handle/10482/18562

Lago, V. M. (2008). As práticas em avaliação psicológica nos casos de disputa de guarda de filhos no Brasil (Dissertação de mestrado em Psicologia, Universidade Federal do Rio Grande do Sul, Porto Alegre, RS, Brasil). Recuperado em http:// www.lume.ufrgs.br/handle/10183/12595

Lago, V. M. (2012). Construção de um Sistema de Avaliação do Relacionamento Pais-Filhos sob Disputa Judicial (Tese de doutorado em Psicologia, Universidade Federal do Rio Grande do Sul, Porto Alegre, RS, Brasil). Recuperado em https://www.lume.ufrgs.br/bitstream/handle $/ 10183 / 56830 / 000855861$.pdf? sequence $=1$

Lei $\mathrm{n}^{\circ}$ 6.515, de 26 de dezembro de 1977. (1977, 26 dez.). Regula os casos de dissolução da sociedade conjugal e do casamento, seus efeitos e respectivos processos, e dá outras providências. Diário Oficial da União. Recuperado em http:// www.planalto.gov.br/ccivil 03/leis/16515.htm

Lei $n^{\circ}$ 8.069, de 13 de julho de 1990. (1990, 13 jul.). Dispõe sobre o Estatuto da Criança e do Adolescente e dá outras providências. Diário Oficial da União. Recuperado em http://www.planalto. gov.br/ccivil_03/leis/16515.htm

Lei $\mathrm{n}^{\circ}$ 10.406, de 10 de janeiro de 2002. (2002, 10 jan.). Institui o Código Civil. Diário Oficial da União. Recuperado em http://www.planalto. gov.br/ccivil_03/leis/2002/L10406.htm

Lei ${ }^{\circ} 11.698$, de 13 de junho de 2008. (2008, 13 jun.). Altera os arts. 1.583 e 1.584 da Lei n 10.406, de 10 de janeiro de 2002 - Código Civil, para instituir e disciplinar a guarda compartilhada. Diário Oficial da União. Recuperado em http://www. planalto.gov.br/ccivil_03/_Ato2007-2010/2008/ Lei/L11698.htm

Lei $\mathrm{n}^{\mathrm{o}}$ 13.058, de 22 de dezembro de 2014. (2014, 22 dez.) Altera os arts. $1.583,1.584,1.585$ e 1.634 da Lei no 10.406, de 10 de janeiro de 2002 (Código Civil), para estabelecer o significado da expressão "guarda compartilhada" e dispor sobre sua aplicação. Diário Oficial da União. Recuperado em http://www.planalto.gov.br/ccivil_03/ Ato2011-2014/2014/Lei/L13058.htm.

Maiorki, S. (2014). Elaboração, aplicação e avaliação psicológica de um protocolo para casos de disputa de guarda (Dissertação de mestrado em Psicologia, Universidade Tuiuti do Paraná, Curitiba, PR, Brasil). Recuperado em http://tede.utp. br/tde_busca/arquivo.php?codArquivo $=667$

Meister, A. F. (2013). Aplicação da guarda compartilhada após a Lei no 11.698 de 2008 (Dissertação de mestrado em Psicologia, Universidade Tuiuti do Paraná, Curitiba, PR, Brasil). Recuperado em http://tede.utp.br/tde_busca/arquivo. php? $\operatorname{codArquivo}=578$

Oliveira, P. M. (2013). Lei do bem dizer e do dizer o bem: Uma contribuição da psicanálise para o instituto jurídico da guarda e da adoção (Dissertação de mestrado em Psicologia Clínica, Universidade de São Paulo, SP, Brasil). Recuperado em http://www.teses.usp.br/teses/disponiveis/47/47133/tde-09102013-111732/pt-br.php

Pinto, E. A., Rodrigues, C. A., Suzano, S. A., Meirelles, D. S., \& Figueiredo, M. R. S. (2013). Judicialização da guarda de filhos menores. $A L U$ MNI-A Revista Jurídica do CACO, 1(1), 1-16. Recuperado em http://revistaalumni.com.br/teste/ojs-2.4.2/index.php/ALUMNI/article/view/7

Queiroz, K. R. (2010). O princípio do melhor interesse da criança: Explorações psicanalíticas sobre a disputa da guarda dos filhos (Dissertação de mestrado em Psicologia, Universidade de Fortaleza, CE, Brasil). Recuperado em http://bdtd. ibict.br/vufind/Record/UFOR_2c6b57db03d483 $7083 \mathrm{fd} 40 \mathrm{ba} 162 \mathrm{bb} 624$

Schneebeli, F. C. (2011). "Com quem os filhos ficarão?": Representações sociais da guarda após a separação conjugal (Dissertação de mestrado em Psicologia, Universidade Federal do Espírito Santo, Vitória, ES, Brasil). Recuperado em http://portais4.ufes.br/posgrad/teses/ tese_3967_.pdf

Silva, M. L. C. M. (2009). A parentalidade no contexto da guarda compartilhada (Dissertação de mestrado em Psicologia Clínica, Universidade Católica de Pernambuco, Recife, PE, Brasil) Recuperado em http://www.unicap.br/tede/tde_ busca/arquivo.php?codArquivo=209 